\title{
Correlation Equations for Metal-side Mass Transfer in a Slag-Metal Reaction System with Gas Injection Stirring*
}

\author{
By Masahiro HIRASAWA, ,* Kazumi MORI,** Masamichi SANO,** \\ Yuhji SHIMATANI*** and Yoshimitsu OKAZAKI****
}

\section{Synopsis}

An analytical study has been made on the metal side mass transfer in a slag-metal reaction system with gas injection stirring. Considerations have been given of the relation between metal side mass transfer and the fluid flow in the vicinity of the slag-metal interface. On the basis of a theory of turbulent phenomena, metal-side mass transfer coefficients are derived as functions of gas injection stirring conditions. The theoretical equations are rearranged to dimensionless correlation equations.

The mass transfer data obtained by the authors from model studies for molten slag- $\mathrm{Cu}$ reaction system of $\mathrm{Si}$ oxidation at $1250^{\circ} \mathrm{C}$ and the available results of model studies at low temperature (aqueous solution-amalgam system at room temperature and molten salt-molten $\mathrm{Pb}$ system at $450^{\circ} \mathrm{C}$ ) are correlated successfully by the equations obtained in the present study. It is found that the dimensionless correlation equations obtained in the present study are applicable to the data of ladle desulfurization.

Key words: slag-metal reaction; mass transfer; gas injection; oxidation of $\mathrm{Si}$.

\section{Introduction}

In a previous paper ${ }^{1)}$ the authors reported the results of experimental studies made to investigate the effect of gas injection stirring on the metal-side mass transfer with a molten slag-Cu reaction system of $\mathrm{Si}$ oxidation by $\mathrm{FeO}$ in the slag. From these studies it was shown that metal-side mass transfer coefficient was affected complicatedly by the gas injection stirring conditions.

In the present paper the experimental results obtained in the previous studies are analyzed quantitatively on the basis of a hydrodynamic theory of turbulence phenomena.

\section{Theoretical Examination}

\section{Relation between Metal-side Mass Transfer Coefficient and Stirring Power of Gas Injection}

According to the previous studies, ${ }^{1)}$ the dependence of apparent metal-side mass transfer coefficient of $\mathrm{Si}$, $k_{\mathrm{Si}}^{\prime}$, on the injected Ar gas flow rate, $V_{\mathrm{g}}$, and the metal depth, $h_{\mathrm{M}}$, varied at transitional gas flow rates $\left(V_{\mathrm{g}}^{*}\right.$ and $V_{\mathrm{g}}^{* *}$ ) and transitional metal depth $\left(h_{\mathrm{M}}^{*}\right)$, respectively. ${ }^{\dagger}$ The explored $V_{\mathrm{g}}$ range was divided into three regions according to the dependence of $k_{\mathrm{Si}}^{\prime}$ on $V_{\mathrm{g}}$ :

(i) Region I $\left(V_{\mathrm{g}}<V_{\mathrm{g}}^{*}\right): k_{\mathrm{S} 1}^{\prime}$ is proportional to
$V_{\mathrm{g}}^{1 / 2}$

(ii) Region II $\left(V_{\mathrm{g}}^{*}<V_{\mathrm{g}}<V_{\mathrm{g}}^{* *}\right)$ : The effect of the increase in $V_{\mathrm{g}}$ on the increase in $k_{\mathrm{Si}}^{\prime}$ is considerably smaller than in Region I.

(iii) Region III $\left(V_{\mathrm{g}}>V_{\mathrm{g}}^{* *}\right)$ : The extent of the increase in $k_{\mathrm{S} \text { i }}^{\prime}$ with $V_{\mathrm{g}}$ increases again.

In Regions I and II, $k_{\mathrm{Si}}^{\prime}$ increases with $h_{\mathrm{M}}$ when $h_{\mathrm{M}}<$ $h_{\mathrm{M}}^{*}$. At $h_{\mathrm{M}}>h_{\mathrm{M}}^{*} k_{\mathrm{Si}}^{\prime}$ becomes independent of $h_{\mathrm{M}}$. It was considered that in Region III the change in actual interfacial area caused by gas stirring at high flow rates brought about the rapid increase in $k_{\mathrm{Si}}^{\prime}$ with $V_{\mathrm{g}}$. Below, discussions are focused mainly on the cases corresponding to the $V_{\mathrm{g}}$ ranges of Regions I and II where the apparent $k_{\mathrm{Si}}^{\prime}$ can be regarded approximately as a real metal-side mass transfer coefficient.

Here, the relation between the metal-side mass transfer coefficient and the stirring power given from gas injection into the metal phase is discussed. The stirring power given by gas injection, $\dot{\varepsilon}$, is expressed approximately by Eq. (1) when the depths of metal and slag phases are small. ${ }^{2}$

$$
\dot{\varepsilon} \fallingdotseq V_{\mathrm{g}} g h_{I} \rho_{\mathrm{M}}
$$

where, $V_{\mathrm{g}}$ : the flow rate of injected gas at the conditions of bath temperature and at $1 \mathrm{~atm}$ pressure

$g$ : the accerelation of gravity

$h_{I}$ : the distance between the slag-metal interface and nozzle tip (injection depth of metal phase)

$\rho_{\mathrm{M}}$ : the density of metal phase.

As given by Eq. (1), the stirring power input to the metal phase is proportional to the injection depth of metal phase. Hence, the experimental $k_{\mathrm{Si}}^{\prime}-h_{\mathrm{M}}$ relations given in the previous paper is rearranged to $k_{\mathrm{Si}}^{\prime}-h_{I}$ relations as illustrated in Fig. 1 . Here, $h_{I}=$ $h_{\mathrm{M}}-0.5(\mathrm{~cm})$. The transitional injection depth of metal phase, $h_{I}^{*}$, is obtained from the figure. It is indicated in the figure that, in Regions I and II, $k_{\mathrm{S} 1}^{\prime}$ is proportional to $h_{I}^{1 / 2}$ at $h_{I}<h_{I}^{*}$, while at $h_{I}>h_{I}^{*}$ $k_{\mathrm{Si}}^{\prime}$ is independent of $h_{I}$. The transitional injection depth $h_{I}^{*}$ tends to decrease with increasing $V_{\mathrm{g}}$.

Taking the two relationships into consideration, that is, $k_{\mathrm{Si}}^{\prime} \propto\left(V_{\mathrm{g}} / d_{\mathrm{c}}^{2}\right)^{1 / 2}$ at $V_{\mathrm{g}}<V_{\mathrm{g}}^{*}$ (Region I) (Fig. 10

\footnotetext{
* Manuscript received on September 18, 1986; accepted in the final form on December 12, 1986. C 1987 ISIJ

** Department of Metallurgy, Faculty of Engineering, Nagoya University, Furo-cho, Chikusa-ku, Nagoya 464.

*** Formerly Graduate School, Nagoya University. Now at Engineering Department, Nachi-Fujikoshi Corporation, Ishigane, Toyama 930 .

**** Graduate School, Nagoya University, Furo-cho, Chikusa-ku, Nagoya 464.

$\dagger \quad$ Below, "the previous paper" ${ }_{11}$ is referred as "the previous paper" simply. The symbols used in the previous paper and also the classification of experimental data (Region I etc.) are used in the same manner as in the previous paper.
} 


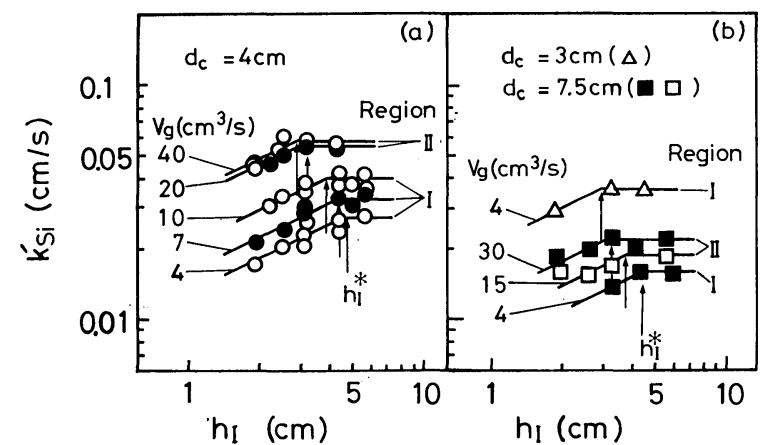

Fig. 1. Relation between apparent mass transfer coefficient of $\mathrm{Si}, k_{\mathrm{Si}}^{\prime}$, and injection depth of metal phase, $h_{I}$.

of the previous paper) and $k_{\mathrm{Si}}^{\prime} \propto h_{I}^{1 / 2}$ at $h_{I}<h_{I}^{*}$, shown in Fig. 1, one will examine the relation between $k_{\mathrm{Si}}^{\prime}$ and $\left(V_{\mathrm{g}} h_{I} / d_{\mathrm{c}}^{2}\right)$ at $V_{\mathrm{g}}<V_{\mathrm{g}}^{*}$ (Region I) and $h_{I}<h_{I}^{*}$. As shown in Fig. 2, the experimental data are correlated reasonably by the equation, $k_{\mathrm{Si}}^{\prime} \propto$ $\left(V_{\mathrm{g}} h_{I} / d_{\mathrm{c}}^{2}\right)^{1 / 2}$. In this case, the relation $k_{\mathrm{Si}}^{\prime} \propto(\dot{\varepsilon} / A)^{1 / 2}$, where $A$ is the cross-sectional area of crucible, may be expected to hold. However, the mass transfer data at $V_{\mathrm{g}}>V_{\mathrm{g}}^{*}$ and/or at $h_{I}>h_{I}^{*}$ cannot be correlated by the above simple relation. It is concluded, therefore, that not only the power input $\dot{\varepsilon}$ but also the fluid flow itself in the slag-metal bath have to be taken into account.

2. Significance of Fluid Flow in the Slag-Metal Bath in the Metal-side Mass Transfer Coefficient

\section{Experiments on the Effect of the Slag Depth}

It was suggested from the mass transfer data with two levels of slag depth at $V_{\mathrm{g}}<V_{\mathrm{g}}^{* *}$ that the metalside mass transfer coefficient, $k_{\mathrm{Si}}^{\prime}$, decreased with lowering slag depth, $h_{\mathrm{sl}}$, in the $V_{\mathrm{g}}$ range of Region II $\left(V_{\mathrm{g}}^{*}<V_{\mathrm{g}}<V_{\mathrm{g}}^{* *}\right)$ where the effect of increase in $V_{\mathrm{g}}$ on the increase in $k_{\mathrm{Si}}^{\prime}$ was small. ${ }^{1)}$ Additional experiments have been made here to investigate the effect of slag depth on $k_{\mathrm{Si}}^{\prime}$ in Region II in more detail. In the experiments $h_{\mathrm{s} 1}$ were ranged from 1.2 to $2.0 \mathrm{~cm}$. The injection depth of metal phase, $h_{I}$, was chosen so that $h_{I}>h_{I}^{*}$. Figure 3 shows the results. The symbols $\bigcirc$ and - in the figure designate the data at $d_{\mathrm{c}}=4 \mathrm{~cm}, V_{\mathrm{g}}=40 \mathrm{~cm}^{3} / \mathrm{s}$ and $h_{I}=3.1 \mathrm{~cm}$ and those at $d_{\mathrm{c}}=7.5 \mathrm{~cm}, V_{\mathrm{g}}=30 \mathrm{~cm}^{3} / \mathrm{s}$ and $h_{I}=4.5 \sim 5.5 \mathrm{~cm}$, respectively.

As seen in Fig. 3, in Region II $k_{\mathrm{Si}}^{\prime}$ increases with increasing $h_{\mathrm{s} 1}, k_{\mathrm{Si}}^{\prime}$ being proportional to $h_{\mathrm{s} 1}^{1 / 2}$.

\section{Fluid Flow in the Slag-Metal Bath}

Figure 4 illustrates the possible flow pattern in the slag-metal bath. Presumably flow is induced not only in the metal phase but also in the slag phase by the work done by the buoyant force of the rising bubbles. Here, the fluid flow in the metal phase is considered to be of turbulence because of size of bubbles $\left(d_{\mathrm{B}}=0.7 \sim 1.4 \mathrm{~cm}\right) .{ }^{4,5)}$ However it is not clear from $d_{\mathrm{B}}$ whether the fluid flow in the slag phase becomes of turbulence or not because of high slag viscosity.*

The turbulent fluid motion in the metal phase is

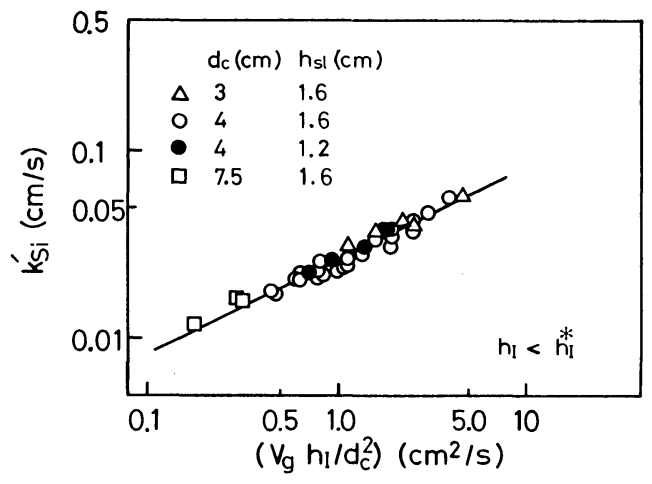

Fig. 2. Relation between $k_{\mathrm{Si}}^{\prime}$ and $\left(V_{\mathrm{g}} h_{I} / d_{\mathrm{c}}^{2}\right)$.

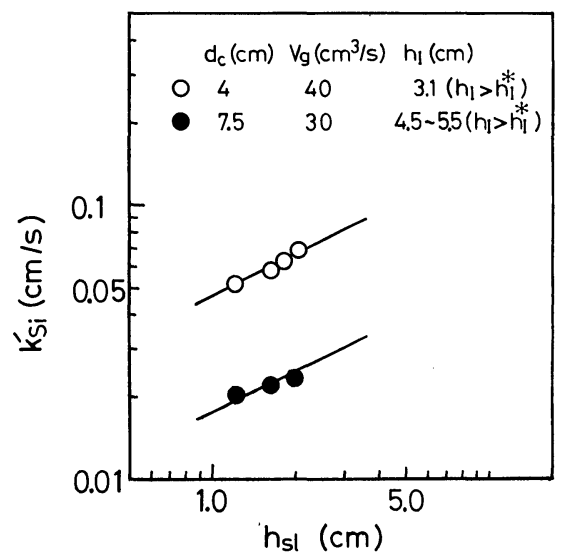

Fig. 3. Relation between $k_{\mathrm{Si}}^{\prime}$ and slag depth, $h_{\mathrm{s} 1}$.

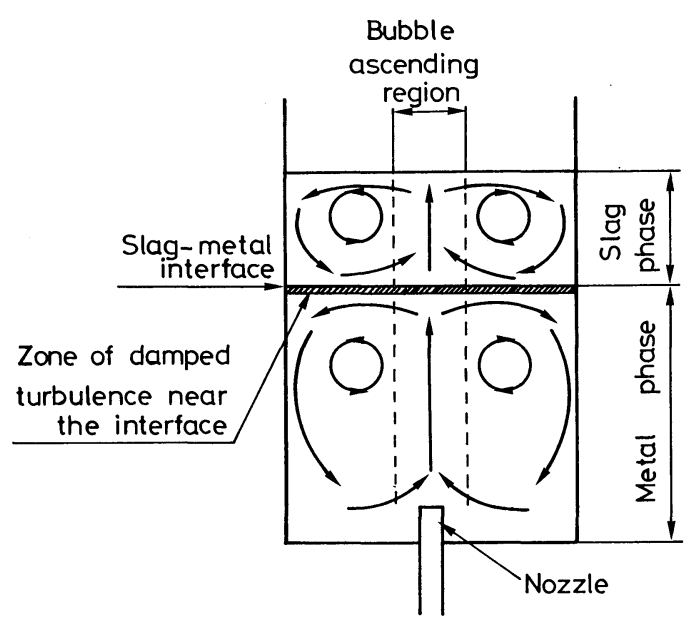

Fig. 4. Schematic representation of the flow patterns in a slag-metal bath.

restrained by the slag-metal interface because of high interfacial tension of the slag-metal system and high viscosity of the slag. In this case "zone of damped turbulence" $"$ is considered to form in the metal phase near the interface, as illustrated in Fig. 4. A boundary film for metal-side mass transfer is postulated to exist in the "zone of damped turbulence". Both the thickness of the "zone of damped turbulence" and the thickness of the boundary film are considered to decrease with intensifying turbulence in the bulk metal phase. Near the interface, however, the flow in the slag phase is in the direction opposite

* The viscosity of the slag of the present study is estimated ${ }^{16,17)}$ to be $4 \sim 10$ poise. 
to that of the flow in the metal phase. It follows that damping of the metal phase turbulence near the interface is strengthened by the increase in momentum transfer from the bulk slag phase to the interface with increasing flow velocity in the slag phase. In this situation the thickness of the " zone of damped turbulence" and the thickness of the metal-side boundary film would be increased.

When the injection gas flow rate is so low that the velocity of flow in the slag phase is negligible in comparison with that in the metal phase because of the large difference in viscosity, metal-side mass transfer is not affected by hydrodynamic conditions of the slag phase. The Region I $\left(V_{\mathrm{g}}<V_{\mathrm{g}}^{*}\right)$ may correspond to this case.

In Region II $\left(V_{\mathrm{g}}^{*}<V_{\mathrm{g}}<V_{\mathrm{g}}^{* *}\right)$, as discussed in the previous paper, the intensification of stirring caused by the increase in $V_{\mathrm{g}}$ leads to only a slight effect on the enhancement of mass transfer near the interface. A possible explanation of the feature of the mass transfer in this region may be given as follows: In Region II it is postulated that the velocity of flow in the slag phase caused from the increased gas flow becomes so large that the slag flow tends to suppress the flow in the metal phase near the interface. Here, the increase in slag depth would result in extending the flow field in the slag phase, leading to the decrease in the extent of the momentum transfer from the slag phase to the metal phase through the slag-metal interface. Thus, it can be considered that $k_{\mathrm{Si}}^{\prime}$ increases with increasing $h_{\mathrm{s} 1}$ (Fig. 3).

\section{Application of Theory of Turbulence Phenomena}

An analytical approach to the metal-side mass transfer will be made by use of the theory of turbulence phenomena developed by Davies. ${ }^{6)}$ Here, the case where the metal-side mass transfer is not affected by the fluid flow in the slag phase, i.e., Region I $\left(V_{\mathrm{g}}<V_{\mathrm{g}}^{*}\right)$, is handled.

On the assumption that the "zone of damped turbulence" is formed in the metal-side liquid near the slag-metal interface, as shown in Fig. 4, the metalside mass transfer coefficient, $k_{\mathrm{M}}$, is given by Eq. (2) according to Davies. ${ }^{6)}$

$$
k_{\mathrm{M}}^{2}=\text { const. } \frac{D_{\mathrm{M}} \rho_{\mathrm{M}} v_{0}^{3}}{\sigma_{e}} \approx \text { const. } \frac{D_{\mathrm{M}} \rho_{\mathrm{M}} v_{0}^{3}}{\sigma}
$$

where, $D_{\mathrm{M}}$ : the diffusion coefficient of solute in the metal phase

$\rho_{\mathrm{M}}:$ the density of the metal

$v_{0}$ : the characteristic velocity which represents the intensity of the turbulence near the metal-side interface.*

The " equivalent" interfacial tension, ${ }^{6)} \sigma_{e}$, represents the sum of the two forces damping eddy motion near the interface, that is, the interfacial tension, $\sigma$, and the pressure caused by gravity. Here, $\sigma_{e}$ can be replaced by $\sigma$ since the interfacial tension of slagmetal system is generally very large. In the deriva- tion of Eq. (2) it is assumed that the influence of turbulence in the slag phase on the metal-side mass transfer is negligible.

Turbulent flow in the metal phase is generated by the power given to the metal phase from gas injection stirring. The kinetic energy of the fluid in the metal phase is, then, dissipated as heat in the turbulent flow. The rate of loss of kinetic energy per unit mass of the metal, $P_{\mathrm{M}}$, is given by Eq. (3). ${ }^{6}$ )

$$
P_{\mathrm{M}}=\frac{\left(\tilde{v}^{\prime}\right)^{3}}{l_{e}} \approx \frac{v_{0}^{3}}{l_{e}}
$$

where, $\tilde{v}^{\prime}:$ the root-mean-square value of fluctuation velocity

$l_{e}$ : the mean eddy scale of the energy containing eddies.

Measurements of turbulence made by Robertson and Staples ${ }^{7)}$ in a water bath with a hot wire anemometer showed that with a "shallow" bath $(\sim 2.5 \mathrm{~cm})$ turbulence in the bubble ascending region did not become fully developed. In this case a layer of high turbulence was formed close to the surface. With a "deep" bath $(\sim 6 \mathrm{~cm})$ turbulence in the bubble ascending region became fully developed. In this case the thickness of the layer of high turbulence and the intensity of turbulence within this layer increased considerably. ${ }^{7,8)}$ In the metal phase of the present slag- $\mathrm{Gu}$ system, the development of turbulence and the increase in thickness of highly turbulent layer with increasing metal depth are presumably similar to those in the water model.

The intensity of turbulence is assumed to be so high within a zone of thickness $L$ adjacent to the interface that dissipation of the power input to the metal phase occurs mainly in this zone. $P_{\mathrm{M}}$ is, then, represented by Eq. (4).

$$
P_{\mathrm{M}} \approx \frac{\dot{\varepsilon}}{\rho_{\mathrm{M}}(\pi / 4) d_{\mathrm{c}}^{2} L}=\frac{V_{\mathrm{g}} g h_{I}}{(\pi / 4) d_{\mathrm{c}}^{2} L}
$$

From Eqs. (4) and (3), $v_{0}$ is given by Eq. (5).

$$
v_{0} \approx\left[\frac{V_{\mathrm{g} g h_{I}}}{(\pi / 4) d_{\mathrm{c}}^{2}} \cdot \frac{l_{e}}{L}\right]^{1 / 3}
$$

Robertson and Staples") assumed the scale of " energy containing eddies", $l_{e}$, as $l_{e}=(16 \sigma / \Delta \rho g)^{1 / 2}$. This assumption indicates that the eddy size $l_{e}$ is determined by physical properties of slag and metal phases. In the present study the change in $l_{e}$ with gas injection conditions are taken into consideration for the purpose of making more detailed examination.

When the metal bath is "shallow", that is, when the injection depth of metal phase, $h_{t}$, is small, turbulence in the bubble ascending region is not fully developed. Therefore, turbulent flow in the metal phase may be characterized by the flow in the highly turbulent zone of thickness $L$. Thus, Eq. (6) is assumed.**

\footnotetext{
* The velocity $v_{0}$ is generally called friction velocity in the theory of turbulent shear flows.

** The eddy size $l_{e}$ is proportional to tube diameter for pipe-flow turbulence. ${ }^{6)}$ For turbulence in a stirred tank, $l_{e}$ was found to be determined by length of stirrer blades. ${ }^{9}$
} 


$$
l_{e} \propto L
$$

Using Eqs. (2), (5) and (6), one obtains Eq. (7).

$$
k_{\mathrm{M}} \propto\left[\frac{D_{\mathrm{M}} \rho_{\mathrm{M}}}{\sigma} \cdot \frac{V_{\mathrm{g}} g h_{I}}{(\pi / 4) d_{\mathrm{c}}^{2}}\right]^{1 / 2} \quad \text { [for "shallow" bath] }
$$

When the metal bath is " deep ", turbulence in the bubble ascending region becomes fully developed. Thus $l_{e}$ depends presumably on the factors which characterizes the turbulent flow in the bubble ascending region.* Hence, by analogy with pipe-flow turbulence, ${ }^{6)} l_{e}$ can be assumed as

$$
l_{e} \propto d_{p} R e^{-n} \approx d_{\mathrm{B}} R e^{-n}
$$

where, $d_{p}$ : the diameter of the bubble ascending region in the metal phase.

$R e$ is the Reynolds number where characteristic velocity and length are $\left(4 V_{\mathrm{g}} / \pi d_{\mathrm{c}}^{2}\right)$ and $d_{\mathrm{c}}$, respectively. Bubble diameter, $d_{\mathrm{B}}$, is taken to be $d_{p}$ because the injected gas forms single bubble stream as mentioned in the previous paper. The highly turbulent zone in the metal phase becomes enlarged when the metal phase is " deep". Hence, one can assume

$$
L \propto h_{I}
$$

From Eqs. (2), (5), (8) and (9), Eq. (10) is obtained.

$$
k_{\mathrm{M}} \propto\left[\frac{D_{\mathrm{M}} \rho_{\mathrm{M}}}{\sigma} \cdot \frac{V_{\mathrm{g}} g d_{\mathrm{B}} R e^{-n}}{(\pi / 4) d_{\mathrm{c}}^{2}}\right]^{1 / 2} \quad[\text { for “deep" bath] }
$$

Equation (7) for "shallow" bath predicts that the metal-side mass transfer coefficient is proportional to $\left(V_{\mathrm{g}} h_{I} / d_{\mathrm{c}}^{2}\right)^{1 / 2}$. This explains the feature of the results of experiments at $V_{\mathrm{g}}<V_{\mathrm{g}}^{*}$ (Region $\mathrm{I}$ ) and $h_{I}<h_{I}^{*}$ (Fig. 2). Equation (10) for "deep" bath predicts that the metal-side mass transfer coefficient is proportional to $\left(V_{\mathrm{g}} / d_{\mathrm{c}}^{2}\right)^{1 / 2}$ and independent of $h_{I}{ }^{* *}$ This explains the feature of the results of experiments in Region I and at $h_{I}>h_{I}^{*}$. The decrease in $h_{I}^{*}$ with increasing $V_{g}$, shown in Fig. 1, may be due to the enlargement of the highly turbulent zone with increasing $V_{\mathrm{g}}$. Under the situation where turbulence develops and spreads fully enough in the entire metal bath at increased $V_{\mathrm{g}}$, metal-side mass transfer coefficient may be expressed by the relationship for " deep " bath, even at low $h_{I}$.

\section{Dimensionless Correlations}

1. Relationships Expressed in Terms of Dimensionless Groups for the Gas Flow Rate Range of Region I

Let crucible diameter, $d_{\mathrm{c}}$, and injected gas flow rate per cross-sectional area of crucible, $\left[V_{\mathrm{g}} /\left(\pi d_{\mathrm{c}}^{2} / 4\right)\right]$, be the characteristic length and velocity, respectively. Equations (7) and (10) are rearranged to Eqs. (11) and (12), respectively. (i) For "shallow" bath

$$
S h=C_{1}\left[P e\left(\frac{\rho_{\mathrm{M}} g d_{\mathrm{c}}^{2}}{\sigma}\right)\left(\frac{h_{I}}{d_{\mathrm{c}}}\right)\right]^{1 / 2}
$$

(ii) For " deep" bath

$$
\begin{array}{r}
S h=C_{2}\left[P e\left(\frac{\rho_{\mathrm{M}} g d_{\mathrm{c}}^{2}}{\sigma}\right)\left(\frac{d_{\mathrm{B}} R e^{-n}}{d_{\mathrm{c}}}\right)\right]^{1 / 2} \ldots \ldots \ldots(12) \\
S h=\frac{k_{\mathrm{M}} d_{\mathrm{c}}}{D_{\mathrm{M}}}, P e=\frac{\left(4 V_{\mathrm{g}} / \pi d_{\mathrm{c}}^{2}\right) d_{\mathrm{c}}}{D_{\mathrm{M}}}, R e=\frac{\left(4 V_{\mathrm{g}} / \pi d_{\mathrm{c}}^{2}\right) d_{\mathrm{c}}}{\nu}
\end{array}
$$

where, $\quad \nu$ : kinematic viscosity of metal

$S h$ : Sherwood number

$P e$ : Péclet number

$C_{1}, C_{2}$ : constants.

The apparent metal-side mass transfer coefficient of $\mathrm{Si}, k_{\mathrm{Si}}^{\prime}$, is taken to be $k_{\mathrm{M}}$ of the slag-Gu system.

\section{Transitional Injection Depth of Metal Phase, $h_{I}^{*}$}

Putting Sh of Eq. (11) equal to that of Eq. (12), one has Eq. (13) predicting the transitional injection depth of metal phase for the change from "shallow" to " deep" bath.

$$
\left(\frac{h_{I}^{*}}{d_{\mathrm{B}}}\right) \propto R e^{-n}
$$

The ratio $\left(h_{I}^{*} / d_{\mathrm{B}}\right)$ and the corresponding $R e$ are calculated from the experimental data and plotted in Fig. 5. Here, the experimental data of both Regions I and II are employed on the assumption that the relationship expressed by Eq. (13) which is obtained originally from Eqs. (11) and (12) for Region I is applicable to the results in Region II. This is to be legitimated since the feature of the dependence of $k_{\mathrm{si}}^{\prime}$ on $h_{I}$ is the same in the $V_{\mathrm{g}}$ range of Region I as in that of Region II (Fig. 1).

As seen from Fig. 5, approximately linear relationship between $\log \left(h_{I}^{*} / d_{\mathrm{B}}\right)$ and $\log R e$ is obtained. The slope of the linear line gives $n \fallingdotseq 1 / 3$ (Eq. (13)). Hence, it follows that

$$
\left(\frac{h_{I}^{*}}{d_{\mathrm{c}}}\right) \propto\left(\frac{d_{\mathrm{B}} R e^{-1 / 3}}{d_{\mathrm{c}}}\right)
$$

On the basis of the relationship expressed by Eq.

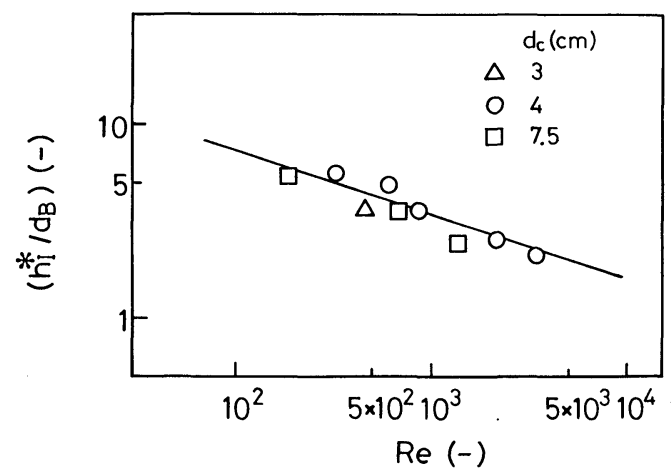

Fig. 5. Relation between $\left(h_{I}^{*} / d_{\mathrm{B}}\right)$ and $R e$.

* The eddy size $l_{e}$ is proportional to tube diameter for pipe-flow turbulence. ${ }^{6}$ ) For turbulence in a stirred tank, $l_{e}$ was found to be determined by length of stirrer blades. ${ }^{\text {) }}$

** In Eq. (10), variation in $d_{\mathrm{B}} R e^{-n}$ with $\left(V_{\mathrm{g}} / d_{\mathrm{c}}^{2}\right)$ is considered to be negligible. 
(14), experimental conditions of the data in Fig. 1 are rearranged in terms of dimensionless groups and represented summarizingly in Fig. 6, where $\left(h_{I} / d_{\mathrm{c}}\right)$ is plotted against $\left(d_{\mathrm{B}} R e^{-1 / 3} / d_{\mathrm{c}}\right)$. Here, represents the experimental data for $h_{I}=h_{I}^{*}$. In the figure, $\left(h_{I} / d_{\mathrm{c}}\right)$ taken from results of water model experiments done by Robertson and Staples ${ }^{7)}$ mentioned in II. 2. 3 is also plotted. The symbols $\Delta$ and $\Delta$ designate the conditions of "shallow" and "deep" bath, respectively. The diameter of bubbles for the water model studies is calculated by using an empirical equation. ${ }^{10)}$ As seen from Fig. 6, the classification of experimental conditions for metal depth by "shallow" or "deep" is well represented both for the molten $\mathrm{Cu}$ model and for the water model by the relationship predicted from Eq. (14) obtained on the basis of $h_{I}^{*}$ data.

\section{Rearrangement of Data in $V_{\mathrm{g}}$ Range of Region $I$ $\left(V_{\mathrm{g}}<V_{\mathrm{g}}^{*}\right)$}

Mass transfer data in $V_{\mathrm{g}}$ range of Region $\mathrm{I}$ are rearranged with using dimensionless correlations, that is, Eq. (11) for "shallow" bath data $\left(h_{I}<h_{I}^{*}\right)$ and Eq. (12) $[n=1 / 3]$ for "deep" bath data $\left(h_{I}>h_{I}^{*}\right)$. Here, $D_{\mathrm{Si}}=6.4 \times 10^{-5} \mathrm{~cm}^{2} / \mathrm{s}^{11)}$ is used. The interfacial tension, $\sigma$, is calculated on the basis of Antonov's rule, that is, $\sigma=\left|\sigma_{M}-\sigma_{S}\right|=930 \mathrm{dyn} / \mathrm{cm}$, where, $\sigma_{M}$ and $\sigma_{S}$ are the surface tensions of molten $\mathrm{Cu}$ and the slag, respectively. Here, $\sigma_{\mathrm{M}}=1320 \mathrm{dyn} / \mathrm{cm}^{12)}$ and $\sigma_{\mathrm{S}}=$ $390 \mathrm{dyn} / \mathrm{cm}^{*}$ are employed. The error involved in the calculated interfacial tension is assumed to be $\pm 30 \%$.** $^{* *}$

Figures 7 and 8 show the correlation of mass transfer data at $h_{I}<h_{I}^{*}$ and at $h_{I}>h_{I}^{*}$, respectively. The symbol $\bigcirc$ designates the present data of slag$\mathrm{Cu}$ system. As seen in these figures, the experimental data for various $V_{\mathrm{g}}, d_{\mathrm{c}}$ and $h_{I}$ are successfully cor-

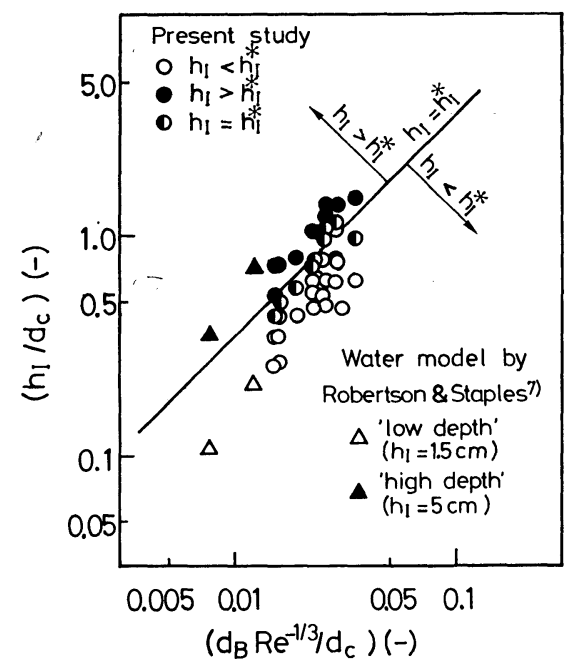

Fig. 6. Transitional injection depth of metal phase, $h_{I}^{*}$, represented by the relation between $\left(h_{I} / d_{\mathrm{c}}\right)$ and $\left(d_{\mathrm{B}} R e^{-1 / 3} / d_{\mathrm{c}}\right)$. related by Eq. (11) $\left(C_{1}=1.0\right)$ or Eq. (12) $\left(C_{2}=6.0\right)$ according as $h_{I}<h_{I}^{*}$ or $h_{I}>h_{I}^{*}$, respectively. The broken lines in the figures correspond to upper and lower limits of error in $\sigma$.

Metal-side mass transfer data of model studies at low temperatures (aqueous solution-amalgam system $^{7,8,14)}$ and molten salt-molten lead system ${ }^{3,8)}$ ) by Richardson, Robertson and co-workers are also plotted in Figs. 7 and $8 .^{* * *}$ These data are regarded to belong to Region I, since they show the relation $k_{\mathrm{M}} \propto V_{\mathrm{g}}^{1 / 2}$. All the data in Figs. 7 and 8 are classified into two groups of $h_{I}>h_{I}^{*}$ and $h_{I}<h_{I}^{*}$ on the basis of Fig. 6. The "high depth" and "low depth " grouping ${ }^{8)}$ by Richardson et al. are in agreement with the present grouping based on $h_{I}^{*}$.

As seen from Figs. 7 and 8, the mass transfer data are successfully correlated by the dimensionless relationships in spite of large differences in the experimental temperature and physical properties between

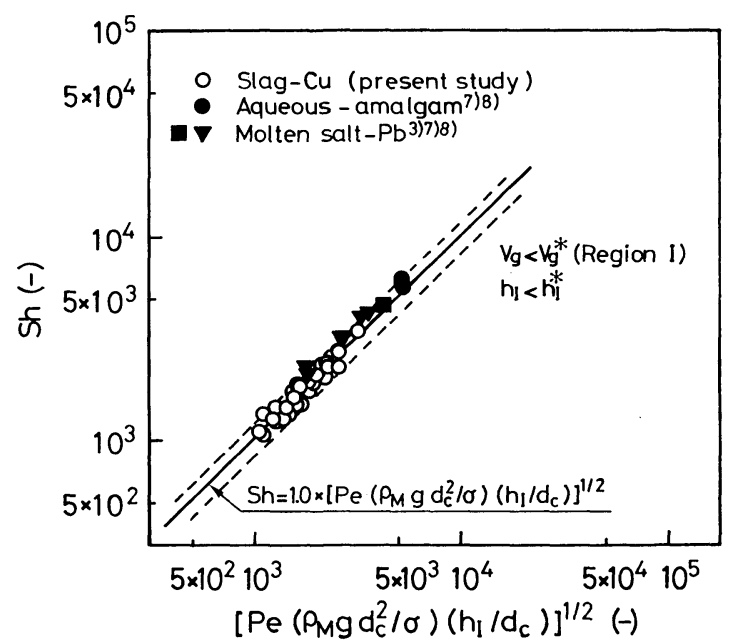

Fig. 7. Dimensionless correlation of mass transfer data at $V_{\mathrm{g}}<V_{\mathrm{g}}^{*}$ and $h_{I}<h_{I}^{*}$.

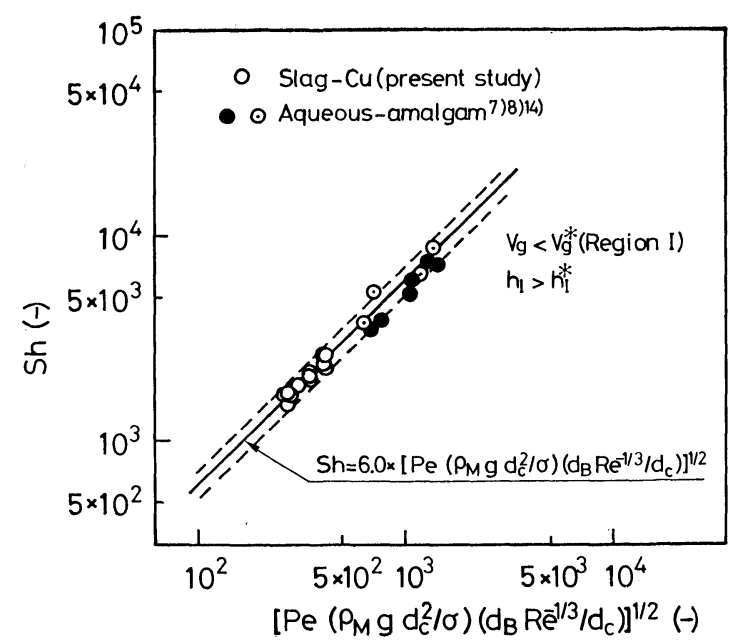

Fig. 8. Dimensionless correlation of mass transfer data at $V_{\mathrm{g}}<V_{\mathrm{g}}^{*}$ and $h_{I}>h_{I}^{*}$.

* $\sigma_{S}$ is calculated with "surface tension factors". ${ }^{13)}$

** The validity of Antonov's rule has been examined for available data of slag-metal interfacial tension at high temperature. The deviations of estimated interfacial tension values according to Antonov's rule are mostly within $30 \%$.

*** Bubble diameter $d_{\mathrm{B}}$ were calculated from empirical equation. ${ }^{10}$ ) 
the slag-Gu system and model systems at low temperature. From this fact, it is concluded that Eqs. (11) and (12) hold generally as far as $k_{\mathrm{M}}$ is proportional to $V_{\mathrm{g}}^{1 / 2}$.

\section{Rearrangement of Data in $V_{\mathrm{g}}$ Range of Region $I I$ $\left(V_{\mathrm{g}}>V_{\mathrm{g}}^{*}\right)$}

As already mentioned in $I I .2$. 2, fluid flow in the slag phase is considered to affect the metal-side mass transfer in Region II. This suggests that the physical properties of the slag phase are needed to be taken into account for detailed analyses of the data in this region. However, in $V_{\mathrm{g}}$ range of Region II no data are available which concern with widely varied physical properties of slag phase. Hence, dimensionless correlations obtained for Region I will be used to examine correlations in Region II.

Grouping of data in accordance with metal depth conditions is made on the basis of Fig. 6. The relation, $k_{\mathrm{Si}}^{\prime} \propto h_{\mathrm{Si}}^{1}{ }^{2}$, in Fig. 3 is taken into account. Considering the relationships implied in Eqs. (11) and (12) for Region I, one may postulate the relations

$$
S h=C_{3}\left[P e^{\alpha}\left(\frac{\rho_{\mathrm{M}} g d_{\mathrm{c}}^{2}}{\sigma}\right)^{\beta}\left(\frac{h_{I}}{d_{\mathrm{c}}}\right)\left(\frac{h_{\mathrm{s} 1}}{d_{\mathrm{c}}}\right)\right]^{1 / 2}, \quad\left(h_{I}<h_{I}^{*}\right)
$$

and

$$
S h=C_{4}\left[P e^{\alpha}\left(\frac{\rho_{\mathrm{M}} g d_{\mathrm{c}}^{2}}{\sigma}\right)^{\beta}\left(\frac{d_{\mathrm{B}} R e^{-n}}{d_{\mathrm{c}}}\right)\left(\frac{h_{\mathrm{s} 1}}{d_{\mathrm{c}}}\right)\right]^{1 / 2}, \quad\left(h_{I}>h_{I}^{*}\right)
$$

where, $C_{3}, C_{4}$ : constants

$\alpha, \beta$ : exponents.

The exponents $\alpha$ and $\beta$ are calculated from the experimental data by means of the least square method on the basis of Eqs. (15) and (16). The values of $\alpha=0.425$ and $\beta=0.654$ are obtained.

The success of the dimensionless relationships, i.e., Eq. (15) at $h_{I}<h_{I}^{*}$ and Eq. (16) at $h_{I}>h_{I}^{*}$, in correlating the experimental data in Region II is illustrated in Figs. 9 and 10. As seen from Fig. 10, the agreement between the correlation equation and the data for small crucible $\left(d_{\mathrm{c}}=3 \mathrm{~cm}, \Delta\right)$ is rather poor as compared with that for other $d_{c}$. The ratio of bubble diameter, $d_{\mathrm{B}} \approx 1 \mathrm{~cm}$, to crucible diameter, $d_{\mathrm{c}}=3 \mathrm{~cm}$, is considerably larger than that in the cases of $d_{\mathrm{c}}=$ 4 and $7.5 \mathrm{~cm}$. Namely, in the case of $d_{\mathrm{c}}=3 \mathrm{~cm}$ the ratio of the cross-sectional area of bubble ascending region to that of crucible is larger than in the other cases. This suggests that the fluid flow pattern in the slag-metal bath in the former case is somewhat different from that in the latter cases.

The constants $C_{4}$ and $C_{5}$ are given as $C_{4}=1.0 \times 10^{2}$ and $C_{5}=6.0 \times 10^{2}$ from Figs. 9 and 10 . It is to be noted that the values of the constants are presumably influenced by physical properties of the slag phase. Therefore, the constants of $C_{4}$ and $C_{5}$ may be applicable only to the data for the present slag-Cu system.

\section{Transitional Gas Flow Rates $V_{\mathrm{g}}^{*}$ and $V_{\mathrm{g}}^{* *}$}

\section{Gas Flow Rate $V_{\mathrm{g}}^{*}$}

One can express the transitional gas flow rate $V_{\mathrm{g}}^{*}$

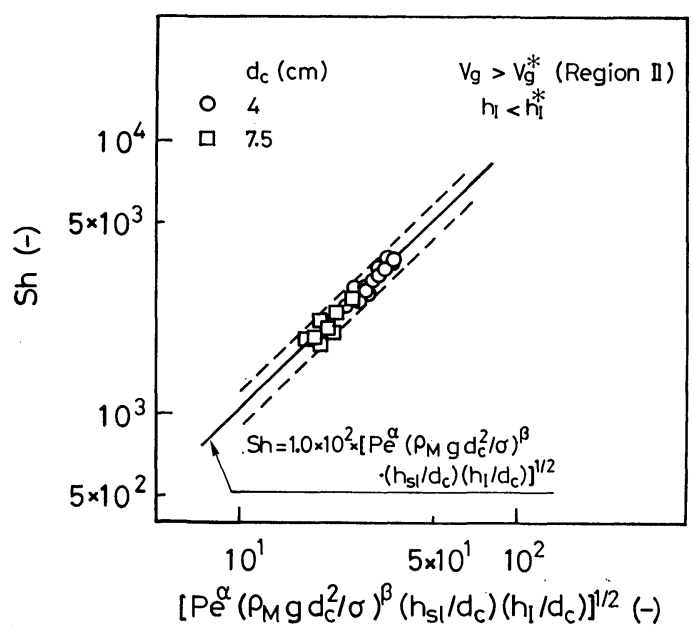

Fig. 9. Dimensionless correlation of mass transfer data at $V_{\mathrm{g}}>V_{\mathrm{g}}^{*}$ and $h_{I}<h_{I}^{*} . \quad \alpha=0.425, \beta=0.654$.

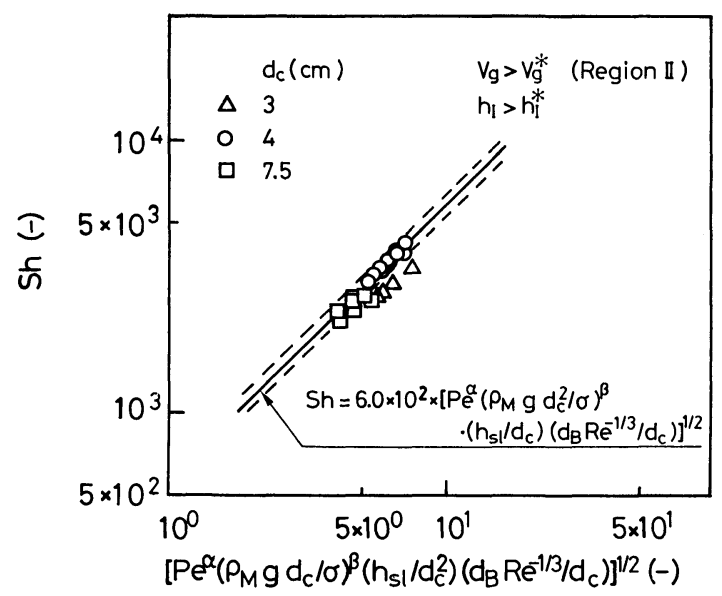

Fig. 10. Dimensionless correlation of mass transfer data at $V_{\mathrm{g}}>V_{\mathrm{g}}^{*}$ and $h_{I}>h_{I}^{*} . \quad \alpha=0.425, \beta=0.654$.

as a function of crucible diameter, $d_{c}$, and slag depth, $h_{\mathrm{s} 1}$, using dimensionless relationships for Regions I and II.

At $V_{\mathrm{g}}=V_{\mathrm{g}}^{*}$, the transitional Péclet number, $P e^{*}$, may be defined as $P e^{*}=\left[\left(4 V_{\mathrm{g}}^{*} / \pi d_{\mathrm{c}}^{2}\right) d_{\mathrm{c}} / D_{\mathrm{M}}\right]$. Putting the right hand side of Eq. (11) equal to that of Eq. (15) for "shallow" bath, or putting the right hand side of Eq. (12) equal to that of Eq. (16) for " deep" bath, one may write

$$
\left(\frac{h_{\mathrm{s} 1}}{d_{\mathrm{c}}}\right)=10^{-4} P e^{*(1-\alpha)}\left(\frac{\rho_{\mathrm{M}} g d_{\mathrm{c}}^{2}}{\sigma}\right)^{(1-\beta)}
$$

where, $\alpha=0.425$

$$
\beta=0.654 \text {. }
$$

According to Eq. (17), $V_{\mathrm{g}}^{*}$ is influenced by $d_{\mathrm{c}}$ and $h_{\mathrm{s} 1}$.

The relationship expressed by Eq. (17) is illustrated in Fig. 11. The symbols $\bigcirc, \bigcirc, \square$ and $\Delta$ designate experimental data for varied conditions; the solid line represents Eq. (17). Except the datum designated by $\Delta$ at $d_{\mathrm{c}}=3 \mathrm{~cm}$, the experimental data lie on the line; $V_{\mathrm{g}}^{*}$ is successfully represented by Eq. (17). The deviation of the data for $d_{\mathrm{c}}=3 \mathrm{~cm}$ from the line may be due to hydrodynamic phenomena in the slagmetal bath somewhat different from that in the cases of $d_{\mathrm{c}}=4$ and $7.5 \mathrm{~cm}$, as mentioned in $I I I .4$. 


\section{Transitional Gas Flow Rate $\boldsymbol{V}_{\mathrm{g}}^{* *}$}

The gas flow rates $V_{\mathrm{g}}^{* *}$, where transition from Region II to Region III occurs are obtained from experimental results of the previous paper. In Fig. $12 V_{\mathrm{g}}^{* *}$ at $h_{I}=3.1 \sim 3.2 \mathrm{~cm}$ and $h_{\mathrm{s} 1}=1.6 \mathrm{~cm}$ are plotted against crucible diameter, $d_{\mathrm{c}}$. As seen in the figure, $V_{\mathrm{g}}^{* *}$ is independent of $d_{\mathrm{c}}$. This may be explained as follows: the increase in fluid velocity in the bubble ascending regions of metal and slag phases with increasing $V_{\mathrm{g}}$ causes mechanical instability at the slag-metal interface independently of $d_{\mathrm{c}}$. However, detailed information about the feature of mechanical instability at the slag-metal interface is not available at present. Further studies on the relation between $k_{\mathrm{Si}}^{\prime}$ and gas injection stirring conditions in Region III of $V_{\mathrm{g}}>V_{\mathrm{g}}^{* *}$ are being carried out.

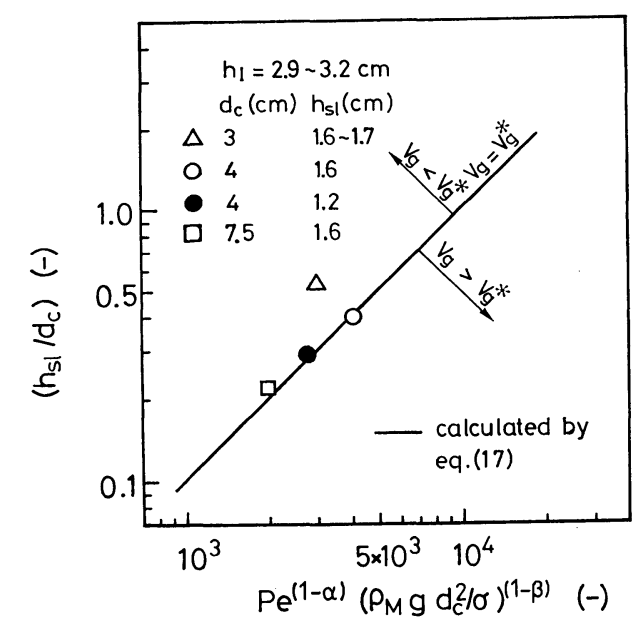

Fig. 11. Transitional gas flow rate, $V_{\mathrm{g}}^{*}$, represented by the relation between $\left(h_{\mathrm{s} 1} / d_{\mathrm{c}}\right)$ and $P e^{(1-\alpha)}\left(\rho_{\mathrm{M}} g d_{\mathrm{c}}^{2} /\right.$ $\sigma)^{(1-\beta)} . \quad \alpha=0.425, \beta=0.654$.

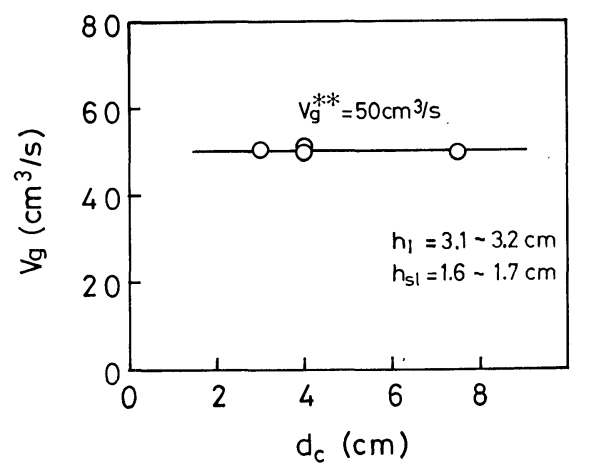

Fig. 12. Relation between the transitional gas flow rate $V_{\mathrm{g}}^{* *}$ and $d_{\mathrm{c}}$.

\section{Summarizing Remarks}

Table 1 shows summarizingly dimensionless correlation equations and the range of validity of the equations obtained in the present study.

Here, the application of the present relationship to the practical refining process is examined.

Riboud and Olette ${ }^{15)}$ reported that, in ladle desulfurization refining in several French steel plants, metal side mass transfer coefficient of $\mathrm{S}, k_{\mathrm{S}}$, was expressed by $k_{\mathrm{S}}=\gamma\left(4 V_{\mathrm{g}} D_{\mathrm{S}} / \pi d_{\mathrm{c}}^{2}\right)^{1 / 2}$, where $\gamma=500 \mathrm{~m}^{-0.5}$. Since $k_{\mathrm{S}} \propto V_{\mathrm{g}}^{1 / 2}$, the correlation equations in Region I may be used. The operating conditions of $250 \mathrm{t}$ ladle, ${ }^{15)}$ i.e., $V_{\mathrm{g}}=0.21 \mathrm{~m}^{3} / \mathrm{s}$ (at $1600^{\circ} \mathrm{C}, 1$ atm pressure), $\pi d_{\mathrm{c}}^{2} / 4=12.5 \mathrm{~m}^{2}$ and $h_{\mathrm{M}}=2.9 \mathrm{~m}$, are taken for the sake of discussion. Assuming $h_{I}=h_{\mathrm{M}}$ and putting $d_{p}=0.37 h_{\mathrm{M}},{ }^{10)}$ one may see from Fig. 6 that $h_{I}>h_{I}^{*}$. In this case, from Table $1, \gamma=6.0\left(\rho_{\mathrm{Fe}} g d_{p} R e^{-1 / 3} / \sigma\right)^{1 / 2}$. Putting $\rho_{\mathrm{Fe}} \approx 7 \times 10^{3} \mathrm{~kg} / \mathrm{m}^{3}, \quad \mu_{\mathrm{Fe}} \approx 5 \times 10^{-3} \quad \mathrm{~Pa} \cdot \mathrm{s}$ and $\sigma \approx 1 \mathrm{~N} / \mathrm{m}$ at $1600^{\circ} \mathrm{C}$, one obtains $\gamma \approx 300 \mathrm{~m}^{-0.5}$. This estimated value, $\gamma \approx 300 \mathrm{~m}^{-0.5}$, is in reasonably good agreement with the observed value, $\gamma=500 \mathrm{~m}^{-0.5}$. This indicates that the dimensionless equations obtained from the data of model experiments of small scale are applicable to the data of large scale refining processes.

\section{Conclusion}

Metal-side mass transfer data of the model experiments for oxidation of $\mathrm{Si}$ in molten $\mathrm{Cu}$ by $\mathrm{FeO}$ in the slag affected by gas injection stirring have been analyzed with taking into consideration the fluid flow in the slag-metal bath. On the basis of a hydrodynamic theory of turbulence phenomena, analytical functions are obtained for expressing the relation between the metal-side mass transfer coefficient and the gas injection stirring conditions. From the analytical functions dimensionless correlation equations are derived. The range of validity of each dimensionless equation is obtained with using experimental data. The data of the present study and those of available model studies at low temperatures are correlated successfully by the equations obtained in the present study. It is considered that the dimensionless correlation equations of the present paper can be applicable in principle to the data of large scale refining processes.

\section{REFERENCES}

1) M. Hirasawa, K. Mori, M. Sano, A. Hatanaka, Y. Shimatani and Y. Okazaki: Trans. ISIJ, 27 (1987), 277.

2) M. Sano and K. Mori: Tetsu-to-Hagané, 68 (1982), 2451.

Table 1. Dimensionless correlation equations and transitional conditions obtained from the present study.

\begin{tabular}{|c|c|c|}
\hline & $V_{\mathrm{g}}<V_{\mathrm{g}}^{*}($ Region $\mathrm{I})$ & $V_{\mathrm{g}}^{*}<V<_{\mathrm{g}} V_{\mathrm{g}}^{* *}($ Region II $)$ \\
\hline$h_{I}<h_{I}^{*}$ & $S h=1.0 \times\left[P e\left(\rho_{\mathrm{M}} g d_{\mathrm{c}}^{2} / \sigma\right)\left(h_{I} / d_{\mathrm{c}}\right)\right]^{1 / 2}$ & $S h=1.0 \times 10^{2} \times\left[P e^{\alpha}\left(\rho_{\mathrm{M}} g d_{\mathrm{c}}^{2} / \sigma\right)^{\beta}\left(h_{I} / d_{\mathrm{c}}\right)\left(h_{\mathrm{s} 1} / d_{\mathrm{c}}\right)\right]^{1 / 2}$ \\
\hline$h_{I}>h_{I}^{*}$ & $S h=6.0 \times\left[P e\left(\rho_{\mathrm{M}} g d_{\mathrm{c}}^{2} / \sigma\right)\left(d_{\mathrm{B}} R e^{-1 / 3} / d_{\mathrm{c}}\right)\right]^{1 / 2}$ & $S h=6.0 \times 10^{2} \times\left[P e^{\alpha}\left(\rho_{\mathrm{M}} g d_{\mathrm{c}}^{2} / \sigma\right)^{\beta}\left(d_{\mathrm{B}} R e^{-1 / 3} / d_{\mathrm{c}}\right)\left(h_{\mathrm{s} 1} / d_{\mathrm{c}}\right)\right]^{1 / 2}$ \\
\hline $\begin{array}{l}\alpha=0.425, \beta=0.654 \\
\text { Transitional conditions : }\end{array}$ & $\begin{array}{ll}: h_{I}^{*}:\left(h_{I}^{*} / d_{\mathrm{c}}\right)=36 \times\left(d_{\mathrm{B}} R e^{-1 / 3} / d_{\mathrm{c}}\right) \\
V_{\mathrm{g}}^{*}:\left(h_{\mathrm{s} 1} / d_{\mathrm{c}}\right)=10^{-4} \times P e^{*(1-\alpha)}\left(\rho_{\mathrm{M}} g d_{\mathrm{c}}^{2} / \sigma\right)^{(1-\beta)} \\
V_{\mathrm{g}}^{* *}: \quad V_{\mathrm{g}}^{* *}=50 \mathrm{~cm}^{3} / \mathrm{s}\end{array}$ & $S h=\frac{k_{\mathrm{M}} d_{\mathrm{c}}}{D_{\mathrm{M}}}, \quad P e=\frac{\left(4 V_{\mathrm{g}} / \pi d_{\mathrm{c}}^{2}\right) d_{\mathrm{c}}}{D_{\mathrm{M}}}, \quad R e=\frac{\left(4 V_{\mathrm{g}} / \pi d_{\mathrm{c}}^{2}\right) d_{\mathrm{c}}}{\nu_{\mathrm{M}}}$ \\
\hline
\end{tabular}


3) J. K. Brimacombe and F. D. Richardson: Trans. Inst. Min. Met. Sec. C, 82 (1973), C63.

4) D. Bhaga and M. E. Weber: J. Fluid Mech., 105 (1981), 61.

5) H. Tsuge: Bubbles.Liquid Particles.Dispersion Engineering, ed. by Soc. Chem. Engineers, Japan, Maki Book Co., Tokyo, (1982), 1.

6) J. T. Davies: Turbulence Phenomena, Academic Press, New York, (1972).

7) D.G.G. Robertson and B. B. Staples: Process Engineering of Pyrometallurgy, ed. by M. J. Jones, Inst. Min. Met., London, (1974), 51.

8) F. D. Richardson, D.G.C. Robertson and B. B. Staples: Proceedings Darken Conference on Physical Chemistry in Metallurgy, US Steel Corp. Research Lab., Monroeville, (1976), 25.
9) H. G. Schwartzberg and R. E. Treybal: I \& EC Fundamentals, 7 (1968), 1.

10) M. Sano and K. Mori: Trans. JIM, 17 (1976), 344

11) M. Hirasawa, M. Matsu-ura and K. Mori: J. Japan Inst. Metals, 50 (1986), 796.

12) K. Nogi, K. Ogino, A. McLean and W. A. Miller: Met. Trans., 17B (1986), 163.

13) R. E. Boni and G. Derge: J. Metals, 7 (1956), 53.

14) W. F. Porter, F. D. Richardson and K. N. Subramanian: Heat and Mass Transfer in Process Metallurgy, ed. by A.W.D. Hills, Inst. Min. Met, London, (1967), p. 79.

15) P. V. Riboud and M. Olette: Proceedings of 7 th ICVM, ISIJ, Tokyo, (1982), 879

16) H. R. Shaw: Amer. J. Sci., 272 (1972), 870.

17) K. Mizoguchi, K. Okamoto and Y. Suginohara: J. Japan Inst. Metals, 46 (1982), 1055. 